\title{
Two-week intensive locomotor training improves balance and mobility of a person with chronic incomplete C4 tetraparesis
}

\author{
Abby E. Linford ${ }^{1}$, Joseph C. Wegley ${ }^{2}$, Kathryn Blackadar², Geraldine Brunner-Lam ${ }^{1}$ and Rolando T. Lazaro ${ }^{1 *}$
}

*Correspondence: rlazaro@samuelmerritt.edu

\begin{abstract}
Background: Literature supports the achievement of meaningful functional outcomes following long duration intensive locomotor training (LT). However, these long duration protocols may not be feasible in the current reimbursement environment. The purpose of this case report was to determine if similar functional gains can be achieved through a shorter duration, high intensity training in a person with chronic motor-incomplete $\mathrm{C} 4$ tetraparesis.
\end{abstract}

Case presentation: The patient was a 61-year-old male with a chronic incomplete spinal cord injury (iSCI) level C4 ASIA Impairment Scale (AIS) D (16 months). The intervention was initiated after 13 months of traditional outpatient physical therapy.

Discussion: Course of 10 sessions over two weeks of 90-minute intensive locomotor training comprised of body weight supported treadmill training (BWSTT) with manual assistance, overground training, and independent community integration. Improvements in the Berg Balance Scale, Timed Up and Go, independent walking distances, and self-reported quality of life were noted.

Conclusion: A patient with chronic ( $>1$ year) SCI AIS D improved in walking ability and balance after two weeks of intensive locomotor training. The outcomes followed a similar trend seen with long duration protocols.

Keywords: Balance, motor-incomplete spinal cord injury, locomotor training

\section{Background}

Current research shows that in individuals with incomplete spinal cord injuries (iSCl), locomotor training leads to improved balance and walking and mitigates secondary health conditions related to decreased mobility and falls from impaired balance [1-3]. Experts at the Christopher and Dana Reeve Foundation NeuroRecovery Network (NRN) developed a standardized treatment protocol to maximize functional gains in participants with iSCl using locomotor training (LT) with three elements: body weight supported treadmill training (BWSTT), immediately followed by over ground training, and community integration. Outcomes of the training demonstrated statistically significant improvements in balance and walking after long durations (20-251 sessions) of LT [1-4].

Of the three elements in LT, safe environment and access to the patient's body for manual assistance makes BWSTT the most commonly used method for balance and ambulation rehabilitation in patients with iSCI with American Spinal Injury Association Impairment Scale (AIS) C and D [5,6]. AIS levels can be found in Table 1. Ample research has demonstrated improvements in walking function after BWSTT in this population [1,5-14]. BWSTT allows for high step volume ideal for repetition needed for motor learning. Additionally, results of these studies support the concept that spinal cord circuitry, separate from supraspinal centers, respond to afferent stimuli resulting in a stepping pattern, similar to studies using other mammals [1,15-17].

The second element of the NRN protocol includes overground training to assess carryover from BWSTT and identify functional gait impairments $[\mathbf{1 , 2}]$. A clinical trial by Field-Fote et al., [5] demonstrated greater improvements in functional walking with overground training when compared to treadmill training in 
Linford et al. Physical Therapy and Rehabilitation 2016,

Table 1. American Spinal Injury Association Impairment Scale (AIS)*.

\begin{tabular}{ll}
\hline A & Complete \\
\hline B & $\begin{array}{l}\text { Sensory incomplete: sensory but not motor function is } \\
\text { preserved below the neurological level and includes the sacral } \\
\text { segments S4-S5 }\end{array}$ \\
\hline C & $\begin{array}{l}\text { Motor incomplete: motor function is preserved below the } \\
\text { neurological level, and more than half of key muscles below } \\
\text { the neurological level have a muscle grade less than 3 strength }\end{array}$ \\
\hline D & $\begin{array}{l}\text { Motor incomplete: motor function is preserved below the } \\
\text { neurological level, and at least half of key muscles below the } \\
\text { neurological level have a muscle grade of } 3 \text { or more strength }\end{array}$ \\
\hline E & Normal \\
\hline
\end{tabular}

*From: International Standards for Neurological Classification of Spinal Cord Injury. Available at: http://www.asia-spinalinjury.org/ elearning/ASIA_ISCOS_high.pdf. Accessed on April 21, 2016.

participants with iSCl C/D. The final element integrates task specific training to promote functional walking in a real world environment (community integration) $[\mathbf{1 , 2}, \mathbf{1 8 - 2 0}]$. Individuals practice and improve walking performance by learning to generate and control motor output when initiating steps in real life situations that are both cognitively and physically challenging [5,18-22].

There is a need for shorter, intense bouts of physical therapy designed to maximize functional gains similar to clinical trials with longer treatment duration, and reduce the impact of secondary conditions, minimizing health care costs. The purpose of this case report was to determine if functional gains attained through long duration intensive locomotor training (LT) could be achieved through short duration, high intensity training for a patient with a chronic motor-incomplete C4 tetraparesis.

\section{Case presentation Patient history}

The 61-year-old male patient sustained fractures to cervical vertebrae two through four in a mountain biking accident 16 months ago. The medical diagnosis was SCl level C4 with tetraparesis AIS C.

After the accident, the patient was in acute care for two weeks before transferring to acute rehabilitation, where he completed 63 days of inpatient rehabilitation. He had completed approximately 13 months of outpatient physical therapy, with focus primarily on ambulation with assistive devices, endurance, and whole body strengthening and stability. The locomotor intervention began after a scheduled one-month therapy hiatus. This provided an advantage in that the changes could possibly be linked to the intervention rather than previous therapy. The patient was taking oral Baclofen daily, since initiation of outpatient therapies, for management of increased tone secondary to the $\mathrm{SCl}$.

Prior level of function was independent in all activities including regular walking and bike riding. Current functional level was ambulation one mile daily with wife using bilateral ankle foot orthotics (AFOs) and Lofstrand crutches. The patient's goals for this intervention were to improve strength, increase stamina, become a more proficient walker, and improve balance and stability.

\section{Examination}

Examination of impairment, activity limitations, and participation restrictions were conducted the week prior to the intervention. The patient had spasticity present in all extremity motions on the Modified Ashworth Scale, [23] the greatest was a score of four in right ankle plantar flexors. Proprioception [24] was intact in bilateral great toes, ankles, knees, hips, wrists, and elbows, and impaired in bilateral middle fingers. The AIS score was ASIA D with an upper-extremity (UE) motor score of 43/50 and lower-extremity (LE) motor score of 40/50, with higher motor scores on his left side, UE $>$ LE.

The outcome measures chosen are recommended for patients with $\mathrm{SCI}$ [25]. Berg Balance Scale (BBS) is composed of 14 items and measures static and dynamic balance, quantitatively assessing fall risk [26]. He scored 30/56, indicating medium fall risk (21-40 BBS). The mean BBS score for tetraplegia is 50.7 (7.5 range $=31$ to 56) [27]. Six-Minute Walk Test (6MWT) assesses endurance by measuring the max distance that a person can walk in six minutes [28]. The patient walked 121.92 meters (400 feet) at 0.34 meters per second (mps) ( 0.76 miles per hour) on 6MWT with Lofstrand crutches. Normative data for patients with $\mathrm{SCl}$ American Spinal Injury Association (ASIA) D show a mean of 382.39 meters. Timed 10-Meter Walk Test (10MWT) records the time it takes an individual to ambulate the middle 10 meters in a 20 meter area $[29,30]$. This assesses comfortable and fast gait speed, while minimizing effects of endurance [30]. The patient walked at $0.32 \mathrm{mps}$ at chosen speed, and $0.44 \mathrm{mps}$ on 10MWT at fast speed with Lofstrand crutches. The normative data for chosen speed is a mean of $1.37 \mathrm{mps}$ for individuals with chronic SCI AIS D [31]. The 60-second Sit-to-Stand (STS-60) tests the number of repetitions of sitting down and standing up that an individual can achieve in 60 seconds [32]. STS-60 is a measure of LE strength and force-generating capacity [33]. The patient did 10 repetitions with UE support. The Timed Up and Go (TUG) tests basic functional mobility and risk of falls [30-34]. The patient scored 45.8 seconds with Lofstrand crutches.

The World Health Organization Quality of Life (WHOQOLBREF) assesses quality of life within the context of an individual's culture, value systems, personal goals, standards and concerns [35]. It is highly recommended for use with chronic $\mathrm{SCl}$ AIS C/D $[25,36]$. Scores in four domains are reported between $0-100$, with a higher number indicating a higher quality of life [35]. WHOQOL-BREF domain scores were: Physical Health: 60.7, Psychological Health: 87.5, Social Relationships: 75, Environment: 81.3. The patient indicated scores consistent with normative data for individuals with chronic stroke 
Linford et al. Physical Therapy and Rehabilitation 2016,

in the domain of physical health (mean score of 60.5), and a higher quality of life score for psychological health (59.8), social relationships (mean 62.1), and environment (67.9) [37].

\section{Evaluation and physical therapy diagnosis}

The patient was appropriate for intensive locomotor training according to a literature review indicating that inclusion criteria of incomplete $\mathrm{SCl}$, ASIA classification of $\mathrm{C}$ or $\mathrm{D}$, upper motor neuron involvement, $\mathrm{SCl}$ occurring in the past three years, and ambulating speed of less than $0.8 \mathrm{mps}$ [38].

Patient presented with inability to ambulate independently in the community due to impaired balance, decreased endurance, slow gait speed, muscle weakness, UE and LE tone, decreased motor control and controlled mobility which make him a fall risk.

\section{Intervention}

The intensive locomotor training intervention consisted of 10 sessions, five times per week for two weeks (Table 2). Before each day of intervention baseline heart rate $(\mathrm{HR})$ and blood pressure (BP) were obtained, followed by passive range of motion (PROM) to B LE and doffing of bilateral AFOs.

The intervention was replicated as closely as possible each day. The first task consisted of 40 minutes of BWSTT without UE support, primary physical therapist and physical therapy student assisting with LE advancement and weight shifting (Table 3). Heart rate and Borg Rating of Perceived Exertion (RPE) [39] were obtained every 3 minutes. Standing rest breaks were granted upon patient's request or when the primary physical therapist determined that the patient was not able to maintain proper gait mechanics. Breaks were recorded for time, though the 40 minute clock continued. Unweighting via LiteGait ${ }^{\mathrm{TM}}$

Table 2. Intensive Locomotor Training Protocol.

\begin{tabular}{|c|c|c|c|}
\hline Task & Time & & Task Details \\
\hline Task 1: BWSTT ${ }^{*}$ & 40 mins & & $\begin{array}{l}\text { Constant walking at } \\
\text { speeds } 0.48-0.94 \mathrm{mps}\end{array}$ \\
\hline \multirow{6}{*}{$\begin{array}{l}\text { Task 2: Over } \\
\text { ground activities } \\
\text { with Lofstrand } \\
\text { crutches }\end{array}$} & \multirow[t]{6}{*}{$\begin{array}{l}30 \text { mins } \\
\text { total time }\end{array}$} & 5 mins & $\begin{array}{l}\text { Walking with cognitive } \\
\text { (counting) challenge }\end{array}$ \\
\hline & & 5 mins & Backwards walking \\
\hline & & $5 \mathrm{mins}$ & Lateral stepping \\
\hline & & 5 mins & $\begin{array}{l}\text { Slalom course through } \\
\text { cones }\end{array}$ \\
\hline & & 5 mins & $\begin{array}{l}\text { Stepping over } 2 \mathrm{wx} 4 \mathrm{~h} \\
\text { inch hurdles }\end{array}$ \\
\hline & & 5 mins & Fast walking \\
\hline $\begin{array}{l}\text { Task 3: } \\
\text { Community } \\
\text { ambulation }\end{array}$ & 30 mins & & $\begin{array}{l}\text { Community ambulation } \\
\text { with Lofstrand crutches } \\
\text { and bilateral AFOs }{ }^{* *} \text {. } \\
\text { Supervised by spouse. } \\
\text { Step \# recorded via } \\
\text { pedometer. }\end{array}$ \\
\hline
\end{tabular}

${ }^{\star}$ BWSTT: Body weight supported treadmill training

${ }^{*}$ AFOs: Ankle foot orthotics

(Tempe, AZ) recorded as minimal, moderate, or maximal by feeling tension on the straps. The second task was 30 minutes of over ground activities in a 15.24 meter (50 foot) hallway on low ply carpet, five minutes each of six activities: walking with cognitive (counting) challenge, backwards walking, lateral stepping, slalom course through cones, stepping over $1.5 \times 3.5$ inch hurdles, and fast walking. Total session time was 90-110 minutes per day, including donning/doffing harness before and after treadmill, and transitioning between tasks (Table 3). The third task was independent daily activity 30 minutes community ambulation supervised by the patient's spouse (Table 4). A pedometer for step tracking was worn on the patient's right shoe; the number was multiplied by two for accurate step count.

The tasks were not changed for the purpose of consistency and repeatability during this intervention. Progress was determined by performance on each task. For the first task, tolerance to increased speeds while maintaining optimal mechanics, and decreased HR and reported RPE throughout task was considered progress. Progress in the second task was determined by increased distance covered in each task, and the patient's ability to perform optimal mechanics. For the third task, increased steps taken in $\mathbf{3 0}$ minutes in a variety of

Table 3. Body weight supported treadmill training program.

\begin{tabular}{lllll}
\hline & Week 1 & \multicolumn{3}{c}{ Week 2 } \\
& Day 1 & Day 5 & Day 8 & Day 12 \\
\hline Body weight support & Min & Mod & Mod & Mod \\
Walking time (m:s)* & $33: 20$ & $37: 42$ & $39: 27$ & $38: 40$ \\
Speed range (mps) & $0.48-0.49$ mps & $0.89 \mathrm{mps}$ & $0.89 \mathrm{mps}$ & $0.89 \mathrm{mps}$ \\
Distance $(\mathrm{km})$ & 0.90 & 2.17 & 2.12 & 2.24 \\
\hline
\end{tabular}

$\mathrm{m}: \mathrm{s}=$ minutes:seconds; $\mathrm{mps}=$ meters per second; $\mathrm{km}=$ kilometer

*Total time for task 1 was recorded for 40 minutes. Treadmill time was stopped if the patient took a standing rest break.

Table 4. Community Ambulation Log.

\begin{tabular}{|c|c|c|c|c|}
\hline Day & $\begin{array}{l}\text { Total } \\
\text { steps/day }\end{array}$ & $\begin{array}{l}\text { Steps during Task } \\
\text { 3: Community } \\
\text { Ambulation }\end{array}$ & $\begin{array}{l}\text { Activity } \\
\text { time } \\
\text { (minutes) }\end{array}$ & Location \\
\hline 1 & \multirow{2}{*}{\multicolumn{2}{|c|}{$\begin{array}{l}\text { Pedometer was not recording } \\
\text { at the hip }\end{array}$}} & 40 & Home Depot \\
\hline 2 & & & 30 & Home Depot \\
\hline 3 & 2508 & 1408 & 30 & Neighborhood \\
\hline 4 & 2732 & 1388 & 30 & Neighborhood \\
\hline 5 & 1900 & 288 & 30 & Church \\
\hline *6 & 940 & 456 & 30 & Shopping \\
\hline *7 & 2256 & 1868 & 42 & Community \\
\hline 8 & 1772 & 952 & 30 & Neighborhood \\
\hline 9 & 2192 & 488 & 40 & Neighborhood \\
\hline 10 & 2048 & 938 & 35 & Neighborhood \\
\hline 11 & 2100 & 1368 & 30 & Indoors \\
\hline 12 & 2200 & 1420 & 30 & Indoors \\
\hline
\end{tabular}


Linford et al. Physical Therapy and Rehabilitation 2016,

http://www.hoajonline.com/journals/pdf/2055-2386-3-4.pdf

doi: 10.7243/2055-2386-3-4

environments was considered progress.

\section{Outcomes}

Impairment and activity level post-testing were administered in the week following the intervention. The patient's spasticity was present in all extremity movements on Modified Ashworth Scale, which were generally higher than pre-test. Proprioception was intact, except for bilateral middle fingers. AIS classification was ASIA D with an upper extremity (UE) motor score of $46 / 50$ and lower extremity (LE) motor score of $47 / 50$. The patient scored $40 / 56$ on the BBS, indicating medium fall risk (21-40). A score of 41 would indicate a low fall risk [26]. He walked 150.67 meters at $0.42 \mathrm{mps}$ with bilateral Lofstrand crutches on the 6MWT. The patient improved by 28.75 meters $(23.58 \%)$, however, this did not meet the MDC of 45.8 meters [40]. Scores for Timed 10MWT were $0.29 \mathrm{mps}$ at chosen speed with bilateral Lofstrand crutches $(0.03 \mathrm{mps}$ slower than pre-test), and $0.49 \mathrm{mps}$ at fast speed $(0.05 \mathrm{mps}$ faster than pre test). Fast speed did not meet the minimal detectable change (MDC) of $0.163 \mathrm{mps}$ [41] or $0.13 \mathrm{mps}$ [42]. The 60-second Sit-to-Stand improved by five repetitions (50\%). TUG was 30.5 seconds with Lofstrand crutches, decreased time by 15.3 seconds ( $33.41 \%$ faster), and exceeded the MDC of 10.8 seconds [40]. WHOQOL-BREF domain scores increased in Physical Health, Social Relationships, and Environment, and stayed the same in Psychological Health. Table 5 shows a summary of the outcomes.

Gait analysis pre intervention showed excess hip flexion with use of Lofstrand crutches, and impaired stability of right knee during stance phase of gait, slow gait speed. Post intervention showed excess hip flexion with use of Lofstrand crutches, and increased stability of right knee during stance phase of gait.

The patient met goal for decreased fall risk as shown by improved BBS score by 10 points and TUG by a 15.3 second decrease. Improved ambulation was evident by increased maximum gait speed on 10MWT by $11.36 \%$ using Lofstrand crutches, and improved LE motor score by greater than one point in more than one muscle group, an overall seven point increase. While the patient met the goal of increasing walking distance on the 6MWT, it did not meet the MDC. The patient subjectively reported, "My legs are stronger, knee control is better, I walk more without my AFOs. And walk longer." "This has helped me in all areas."

\section{Discussion}

Prior to the intervention, gait and balance deficits impeded the patient's ability to ambulate long distances and safely negotiate the environment due to increased risk of fall. The patient's goal of "walking better" was directly targeted through intensive LT consisting of BWSTT, overground gait training, and community integration. The design of this intervention aimed to boost functional mobility in a short time frame in order to resume traditional outpatient physical therapy at a higher functional level. The intervention resulted in statistically significant improvement in balance (33\% increase BBS and TUG) and sit-to-stand (50\% increase), as well as individually meaningful improvements in gait speed and mobility (increased 23\% $6 \mathrm{MWT}$, and $11 \% 10 \mathrm{MWT}$ ). Additionally the patient reported improved quality of life (WHOQOL-BREF increased 19\% overall).

A study by the NRN found that intensive LT participants demonstrated improvements in BBS (average of 9.6 points); 6MWT distance (average $63 \mathrm{~m}$ ); 10-MWT speeds (average $0.20 \mathrm{~m} / \mathrm{s}$ ) [22]. However, this study included participants as early as 32 days post injury, within the one year window of rapid recovery. A single patient case study with a 25 -year-old male with chronic iSCI D using NRN standardized protocols

Table 5. Outcome measures.

\begin{tabular}{|c|c|c|c|c|c|}
\hline Measure & Pre- intervention & Post-intervention & Point Change & $\begin{array}{l}\text { Percent } \\
\text { Change }\end{array}$ & $\begin{array}{l}\text { MDC for SCl } \\
\text { (if available) }\end{array}$ \\
\hline Berg Balance Scale (BBS) ${ }^{47}$ & $30 / 56$ & $40 / 56$ & +10 & $+33.33 \%$ & +7 for elderly \\
\hline Six-minute walk test $(6 \mathrm{MWT})^{49}$ & 121.92 meters $(0.34 \mathrm{mps})$ & 150.67 meters $(0.42 \mathrm{mps})$ & +28.75 meters & $+23.58 \%$ & $\begin{array}{l}45.8 \text { meters } \\
(150 \mathrm{ft})\end{array}$ \\
\hline $\begin{array}{l}\text { Timed 10-Meter Walk Test } \\
\text { (10MWT)Chosen speed }\end{array}$ & $0.32 \mathrm{mps}$ & $0.29 \mathrm{mps}$ & $-0.03 \mathrm{mps}$ & $9.38 \%$ slower & $\begin{array}{l}0.254 \mathrm{mps} \\
\text { or } \\
0.13 \mathrm{mps}\end{array}$ \\
\hline $\begin{array}{l}\text { Timed 10-Meter Walk Test } \\
\text { (10MWT) Fast speed }\end{array}$ & $0.44 \mathrm{mps}$ & $0.49 \mathrm{mps}$ & $+0.05 \mathrm{mps}$ & $11.36 \%$ faster & $\begin{array}{l}0.163 \mathrm{mps} \\
\text { or } 0.13 \mathrm{mps}\end{array}$ \\
\hline 60-second Sit-to-Stand & 10 repetitions with $\mathrm{UE}$ & 15 repetitions with $\mathrm{UE}$ & +5 repetitions & $+50.0 \%$ & Not found \\
\hline Timed Up and Go (TUG) & 45.8 seconds & 30.5 Seconds & -15.3 seconds & $\begin{array}{l}33.41 \% \\
\text { faster }\end{array}$ & 10.8 seconds \\
\hline \multicolumn{6}{|c|}{ World Health Organization Quality of Life (WHOQOL-BREF) } \\
\hline Physical & 60.7 & 75 & +14.3 & $+23.6 \%$ & Not found \\
\hline Psychological & 87.5 & 87.5 & 0 & $0 \%$ & -- \\
\hline Social & 75 & 91.7 & +16.7 & $+22.3 \%$ & -- \\
\hline Environment & 81.3 & 90.6 & +9.3 & $+11.4 \%$ & -- \\
\hline
\end{tabular}


Linford et al. Physical Therapy and Rehabilitation 2016,

for LT [23] conducted 100 sessions at five days per week for 90 minutes each visit. Participants demonstrated improvements in $6 \mathrm{MWT}$ ( $111 \%$ increase), and gait speed (23.5\% increase).

Although the patient improved by smaller percentages than the patient in the Morrison [2] case study, results of this intervention were consistent with that of Harkema et al., [3] demonstrating improvements in walking ability, and balance. High frequency/duration is possible in a research setting, though many patients with chronic $\mathrm{SCl}$ do not have the annual insurance benefits or personal financial resources to cover such a large duration of exercise. As demonstrated in this report, intense bouts of short duration training can lead to both statistically significant and meaningful functional gains. Health care costs can be minimized while allowing for transition back to traditional outpatient physical therapy at a higher functional level. The findings have potential significant clinical implications as the short duration protocol described demonstrated a trend toward the same outcomes as the established longer duration protocols. That means that the patient was able to achieve similar functional improvements in shorter period of time, and with less treatment visits. Additional studies are needed to investigate if the gains are maintained in the long term following the shorter duration protocols.

\section{Limitations}

Alternative hypotheses for the positive outcomes of the intervention could be that natural healing is unpredictable and may still be occurring 2 or 3 years after the injury [43]. Learning and neuroplasticity happens in the brain even without rehabilitation $[\mathbf{4 4 , 4 5 ]}$. Variations in hypertonicity may have affected the reliability of the pre and post test outcome measures. The patient reported difficulty with ambulation using Lofstrand crutches while experiencing increased hypertonicity in UEs. Additionally, it may have been beneficial to record RPE and HR during the functional outcome measures in order to determine the intensity of the patient's performance to compare pre and post-test intensity.

It is not possible to state a cause and effect relationship between patient's improvements and the intervention due to $(n=1)$. No generalizations to the broader population of individuals with incomplete spinal cord injury can be made from this case report due to $(n=1)$.

Future research is recommended with a clinical trial using a larger sample size of ambulatory patients with motor-incomplete $\mathrm{SCl}$ and a control group receiving the same number of sessions of intensive locomotor training in a less frequent time frame (two to three visits per week) for 10 sessions. Additionally, research should be done into the most effective treatment duration for locomotor training to boost functional outcomes while reducing health care costs.

\section{Conclusion}

Literature shows that intensive locomotor training as standardized by the NRN in individuals with motor iSCl demonstrate statistically significant improvements in balance, gait speed and mechanics. Modeling after existing intervention protocol by the NRN, our intervention was reduced to ten visits to determine if improvements in gait and balance would be seen in a clinically relevant timeframe. The patient demonstrated improvements in balance and gait mechanics, as well as an improvement in his UE and LE motor scores on the AIS. Additionally, the patient reported improved walking ability and quality of life. Achieving significant and meaningful gains in a shorter time frame could save in health care costs, making them more accessible for all individuals with chronic iSCI C/D.

\section{Competing interests}

The authors declare that they have no competing interests.

Authors' contributions

\begin{tabular}{|l|c|c|c|c|c|}
\hline Authors' contributions & AEL & JCW & KB & GBL & RTL \\
\hline Research concept and design & $\checkmark$ & $\checkmark$ & -- & -- & -- \\
\hline Collection and/or assembly of data & $\checkmark$ & $\checkmark$ & $\checkmark$ & -- & -- \\
\hline Data analysis and interpretation & $\checkmark$ & $\checkmark$ & -- & -- & $\checkmark$ \\
\hline Writing the article & $\checkmark$ & -- & -- & $\checkmark$ & $\checkmark$ \\
\hline Critical revision of the article & $\checkmark$ & -- & -- & $\checkmark$ & $\checkmark$ \\
\hline Final approval of article & $\checkmark$ & $\checkmark$ & $\checkmark$ & $\checkmark$ & $\checkmark$ \\
\hline Statistical analysis & $\checkmark$ & $\checkmark$ & -- & $\checkmark$ & $\checkmark$ \\
\hline
\end{tabular}

\section{Acknowledgement}

We thank Chelsea Lovell and Tessa Carson (both from Samuel Merritt University) and Ryan Linford (Boise State University) for reviewing the manuscript and providing feedback.

Publication history

Editors: Eric Glenn Johnson, Loma Linda University, USA. Mohammad H. Hadadzadeh, Wheeling Jesuit University, USA. Received: 18-Mar-2016 Final Revised: 27-Apr-2016

Accepted: 16-May-2016 Published: 23-May-2016

\section{References}

1. Harkema SJ, Schmidt-Read M, Lorenz DJ, Edgerton VR and Behrman $\mathrm{AL}$. Balance and ambulation improvements in individuals with chronic incomplete spinal cord injury using locomotor training-based rehabilitation. Arch Phys Med Rehabil. 2012; 93:1508-17. | Article | PubMed

2. Morrison SA, Forrest GF, VanHiel LR, Dave M and D'Urso D. NeuroRecovery Network provides standardization of locomotor training for persons with incomplete spinal cord injury. Arch Phys Med Rehabil. 2012; 93:1574-7. | Article | PubMed

3. Datta S, Lorenz DJ and Harkema SJ. Dynamic longitudinal evaluation of the utility of the Berg Balance Scale in individuals with motor incomplete spinal cord injury. Arch Phys Med Rehabil. 2012; 93:1565-73. | Article | PubMed

4. Craig Hospital joins Christopher \& Dana Reeve Foundation NeuroRecovery Network. Craig Hospital. 2013.

5. Field-Fote EC and Roach KE. Influence of a locomotor training approach on walking speed and distance in people with chronic spinal cord injury: a randomized clinical trial. Phys Ther. 2011; 91:48-60. | Article | PubMed Abstract | PubMed FullText

6. Field-Fote EC, Lindley SD and Sherman AL. Locomotor training approaches for individuals with spinal cord injury: a preliminary report of walking-related outcomes. J Neurol Phys Ther. 2005; 29:127-37. | Article I PubMed

7. Barbeau H, Ladouceur M, Mirbagheri MM and Kearney RE. The effect of 
Linford et al. Physical Therapy and Rehabilitation 2016,

locomotor training combined with functional electrical stimulation in chronic spinal cord injured subjects: walking and reflex studies. Brain Res Brain Res Rev. 2002; 40:274-91. | Article | PubMed

8. Gardner MB, Holden MK, Leikauskas JM and Richard RL. Partial body weight support with treadmill locomotion to improve gait after incomplete spinal cord injury: a single-subject experimental design. Phys Ther. 1998; 78:361-74. | Article | PubMed

9. Dietz $\mathrm{V}$, Colombo $\mathrm{G}$ and Jensen $\mathrm{L}$. Locomotor activity in spinal man. Lancet. 1994; 344:1260-3. | Article | PubMed

10. Wernig A, Muller S, Nanassy A and Cagol E. Laufband therapy based on 'rules of spinal locomotion' is effective in spinal cord injured persons. Eur J Neurosci. 1995; 7:823-9. | Article | PubMed

11. Wernig A and Muller S. Laufband locomotion with body weight support improved walking in persons with severe spinal cord injuries. Paraplegia. 1992; 30:229-38. | Article | PubMed

12. Field-Fote $E C$ and Tepavac $D$. Improved intralimb coordination in people with incomplete spinal cord injury following training with body weight support and electrical stimulation. Phys Ther. 2002; 82:707-15. | Article I PubMed

13. Field-Fote EC. Combined use of body weight support, functional electric stimulation, and treadmill training to improve walking ability in individuals with chronic incomplete spinal cord injury. Arch Phys Med Rehabil. 2001; 82:818-24. | Article | PubMed

14. Barbeau H, Danakas $M$ and Arsenault $B$. The effects of locomotor training in spinal cord injured subjects: a preliminary study. Restor Neurol Neurosci. 1993; 5:81-4. | Article I PubMed

15. Edgerton VR, de Leon RD, Tillakaratne N, Recktenwald MR, Hodgson JA and Roy RR. Use-dependent plasticity in spinal stepping and standing. Adv Neurol. 1997; 72:233-47. | PubMed

16. Rossignol IS and Barbeau H. New approaches to locomotor rehabilitation in spinal cord injury. Ann Neurol. 1995; 37:555-6. | Article I PubMed

17. Barbeau $\mathrm{H}$. Locomotor training in neurorehabilitation: emerging rehabilitation concepts. Neurorehabil Neural Repair. 2003; 17:3-11. | Article | PubMed

18. Shumway-Cook A, Patla A, Stewart A, Ferrucci L, Ciol MA and Guralnik JM. Environmental components of mobility disability in communityliving older persons. J Am Geriatr Soc. 2003; 51:393-8. | Article | PubMed

19. Shumway-Cook A, Patla AE, Stewart A, Ferrucci L, Ciol MA and Guralnik $\mathrm{JM}$. Environmental demands associated with community mobility in older adults with and without mobility disabilities. Phys Ther. 2002; 82:670-81. | Article | PubMed

20. Gerin-Lajoie M, Richards CL and McFadyen BJ. The negotiation of stationary and moving obstructions during walking: anticipatory locomotor adaptations and preservation of personal space. Motor Control. 2005; 9:242-69. | PubMed

21. Behrman AL, Bowden MG and Nair PM. Neuroplasticity after spinal cord injury and training: an emerging paradigm shift in rehabilitation and walking recovery. Phys Ther. 2006; 86:1406-25. | Article | PubMed

22. Marino RJ, Barros T, Biering-Sorensen F, Burns SP, Donovan WH, Graves $D E$, Haak M, Hudson LM and Priebe MM. International standards for neurological classification of spinal cord injury. J Spinal Cord Med. 2003; 26 Suppl 1:S50-6. | PubMed

23. Bohannon RW and Smith MB. Interrater reliability of a modified Ashworth scale of muscle spasticity. Phys Ther. 1987; 67:206-7. | Article | PubMed

24. Petty NJ. Neuromusculoskeletal Examination and Assessment: A Handbook for Therapist. Edinburgh: Elsevier Churchill Livingstone. 2006.

25. Kahn J, Newman C and Palma P et al. SCI EDGE outcome measures for motor incomplete (AIS C, D) SCI. Neurology Section. 2013. | Pdf

26. Berg KO, Wood-Dauphinee SL, Williams JI and Maki B. Measuring balance in the elderly: validation of an instrument. Can J Public Health. 1992; 83 Suppl 2:S7-11. | PubMed

27. Lemay JF and Nadeau S. Standing balance assessment in ASIA D paraplegic and tetraplegic participants: concurrent validity of the Berg Balance Scale. Spinal Cord. 2010; 48:245-50. | Article | PubMed

28. Hamidzadeh M and Zelter L. Six minute walk test. StrokEngine Asses. 2013.
29. Fritz S and Lusardi M. White paper: "walking speed: the sixth vital sign" J Geriatr Phys Ther. 2009; 32:46-9. | Article | PubMed

30. van Hedel HJ, Wirz M and Dietz V. Assessing walking ability in subjects with spinal cord injury: validity and reliability of 3 walking tests. Arch Phys Med Rehabil. 2005; 86:190-6. | Article | PubMed

31. Olmos LE, Freixes O, Gatti MA, Cozzo DA, Fernandez SA, Vila CJ, Agrati PE and Rubel IF. Comparison of gait performance on different environmental settings for patients with chronic spinal cord injury. Spinal Cord. 2008; 46:331-4. | Article | PubMed

32. Ozalevli S, Ozden A, Itil O and Akkoclu A. Comparison of the Sit-toStand Test with 6 min walk test in patients with chronic obstructive pulmonary disease. Respir Med. 2007; 101:286-93. | Article | PubMed

33. Csuka M and McCarty DJ. Simple method for measurement of lower extremity muscle strength. Am J Med. 1985; 78:77-81. | Article | PubMed

34. Podsiadlo D and Richardson S. The timed "Up \& Go": a test of basic functional mobility for frail elderly persons. J Am Geriatr Soc. 1991; 39:142-8. | Article | PubMed

35. Skevington SM, Lotfy M and O'Connell KA. The World Health Organization's WHOQOL-BREF quality of life assessment: psychometric properties and results of the international field trial. A report from the WHOQOL group. Qual Life Res. 2004; 13:299-310. | Article | PubMed

36. Lin MR, Hwang HF, Chen CY and Chiu WT. Comparisons of the brief form of the World Health Organization Quality of Life and Short Form-36 for persons with spinal cord injuries. Am J Phys Med Rehabil. 2007; 86:10413. | Article | PubMed

37. Edwards B and O'Connell B. Internal consistency and validity of the Stroke Impact Scale 2.0 (SIS 2.0) and SIS-16 in an Australian sample. Qual Life Res. 2003; 12:1127-35. | Article | PubMed

38. Behrman AL, Lawless-Dixon AR, Davis SB, Bowden MG, Nair P, Phadke C, Hannold EM, Plummer P and Harkema SJ. Locomotor training progression and outcomes after incomplete spinal cord injury. Phys Ther. 2005; 85:1356-71. | Article | PubMed

39. Borg GA. Psychophysical bases of perceived exertion. Med Sci Sports Exerc. 1982; 14:377-81. | Article | PubMed

40. Clifton GL, Donovan WH, Dimitrijevic MM, Allen SJ, Ku A, Potts JR, 3rd, Moody FG, Boake C, Sherwood AM and Edwards JV. Omental transposition in chronic spinal cord injury. Spinal Cord. 1996; 34:193203. | Article | PubMed

41. Burns AS, Delparte JJ, Patrick M, Marino RJ and Ditunno JF. The reproducibility and convergent validity of the walking index for spinal cord injury (WISCI) in chronic spinal cord injury. Neurorehabil Neural Repair. 2011; 25:149-57. | Article | PubMed

42. Lam T, Noonan VK and Eng JJ. A systematic review of functional ambulation outcome measures in spinal cord injury. Spinal Cord. 2008; 46:246-54. | Article | PubMed Abstract | PubMed FullText

43. Incomplete SCls. The early days. Craig Hospital. 2013.

44. Kleim JA and Jones TA. Principles of experience-dependent neural plasticity: implications for rehabilitation after brain damage. I Speech Lang Hear Res. 2008; 51:S225-39. | Article | PubMed

45. Donoghue $D$ and Stokes EK. How much change is true change? The minimum detectable change of the Berg Balance Scale in elderly people. J Rehabil Med. 2009; 41:343-6. | Article I PubMed

\section{Citation:}

Linford AE, Wegley JC, Blackadar K, Brunner-Lam $\mathrm{G}$ and Lazaro RT. Two-week intensive locomotor training improves balance and mobility of a person with chronic incomplete $\mathbf{C} 4$ tetraparesis. Phys Ther Rehabil. 2016; 3:4.

http://dx.doi.org/10.7243/2055-2386-3-4 